\title{
Critical contribution of MCL-1 in EMT-associated chemo-resistance in A549 non-small cell lung cancer
}

\author{
MASAYOSHI TOGE ${ }^{1}$, SATORU YOKOYAMA ${ }^{2}$, SHINICHIRO KATO $^{2}$, HIROAKI SAKURAI ${ }^{2,3}$, \\ KAZUTAKA SENDA ${ }^{1}$, YOSHINORI DOKI ${ }^{1}$, YOSHIHIRO HAYAKAWA ${ }^{2}$, \\ NAOKI YOSHIMURA ${ }^{1}$ and IKUO SAIKI ${ }^{2}$ \\ ${ }^{1}$ Department of Thoracic and Cardiovascular Surgery, ${ }^{2}$ Division of Pathogenic Biochemistry, \\ Institute of Natural Medicine, ${ }^{3}$ Department of Cancer Cell Biology, Graduate School of Medicine \\ and Pharmaceutical Sciences, University of Toyama, Toyama 930-0194, Japan
}

Received November 5, 2014; Accepted December 23, 2014

DOI: 10.3892/ijo.2015.2861

\begin{abstract}
Non-small cell lung cancer (NSCLC) is one of the leading causes of death in all lung cancer patients due to its metastatic spread. Even though cisplatin treatment after surgical resection of the primary tumor has been established as a standard chemotherapy for residual disease including metastatic spread, NSCLC often acquires a resistance against chemotherapy, and metastatic disease is often observed. Amongst many potential mechanisms, epithelial-to-mesenchymal transition (EMT) has been considered as an important process in acquiring both metastatic spread and chemo-resistance of NSCLC. In this study, we identified MCL-1 as a critical molecule for chemoresistance in A549 cells associated with TGF- $\beta$-induced EMT. Importantly, downregulation of MCL-1 by siRNA or inhibition of MCL-1 with pan-BCL2 inhibitor to inhibit MCL-1 was able to overcome the EMT-associated chemo-resistance in A549 cells. Collectively, MCL-1 can be a new therapeutic target for overcoming EMT-associated chemo-resistance in NSCLC patients in the context of post-operative chemotherapies.
\end{abstract}

\section{Introduction}

Non-small cell lung cancer (NSCLC) is one of the common causes of death in the world (1). Although cisplatin treatment after surgery is known as a standard and effective chemotherapy, metastatic spread in NSCLC patients often occurs (2-4). In addition, it is still controversial whether an adjuvant chemotherapy with cisplatin gives a significant survival advantage in stage I NSCLC patients compared with surgery

Correspondence to: Dr Satoru Yokoyama, Division of Pathogenic Biochemistry, Institute of Natural Medicine, University of Toyama, 2630 Sugitani, Toyama 930-0194, Japan

E-mail: yokoyama@inm.u-toyama.ac.jp

Abbreviations: NSCLC, non-small cell lung cancer; EMT, epithelialto-mesenchymal transition

Key words: non-small cell lung cancer, epithelial-to-mesenchymal transition, chemo-resistance, TGF- $\beta$, MCL- 1 alone (5-7). This may lead to the possibility that metastatic NSCLCs already acquire resistance to chemotherapy during tumor progression.

Cancer metastasis is one of the major causes of the high mortality rate in cancer patients and it consists of multiple biological steps, such as dissemination from primary tumor, intravasation, attachment to vessel of target tissue, extravasation, angiogenesis, and subsequent growth at the metastasis site (8). Some of these biological steps have been shown to be related to epithelial-to-mesenchymal transition (EMT) (9-12). Although EMT also has been shown to limit the sensitivities of cancer cells to chemotherapeutic drugs $(13,14)$, the potential mechanism by which cancer cells acquire resistance to anticancer drugs associated with the EMT process is not well defined.

In this study, we demonstrated that EMT in human NSCLC cell line A549 induced by TGF- $\beta$ treatment limits the sensitivities to various anticancer drugs, and further identified MCL-1 as a critical molecule of such EMT-associated chemoresistance of A549 cells. Importantly, we showed that targeting MCL-1 by siRNA delivery or the pan-BCL2 inhibitor treatment could overcome the EMT-associated chemo-resistance in A549 cells.

\section{Materials and methods}

Reagents and plasmids. The reagents used were recombinant human TGF- $\beta$ from Peprotech (London, UK), obatoclax from Selleck Chemicals (Houston, TX, USA), ABT-737 from AdooQ BioScience (Irvine, CA, USA), cisplatin, vinorelbine, gemcitabine and paclitaxel from Wako Pure Chemical Industries (Osaka, Japan). siRNAs against MCL-1 (L-004501-00, J-004501-16, and J-004501-17), Bcl2A1 (L-003306-00), and control (D-00181-02) siRNA were purchased from Thermo Fisher Scientific (Rockford, IL, USA). The human MCL-1 cDNA was amplified from normal human cDNA and subcloned into pcDNA3.1-HA (from David E. Fisher, MGH, MA, USA).

Cell cultures. Human lung adenocarcinoma A549 cells were cultured in RPMI-1640 medium (Life Technologies Corp., Carlsbad, CA, USA) with $10 \%$ fetal bovine serum (FBS; ICN Biomedicals, Aurora, OH, USA), 2 mM L-glutamine 
(Life Technologies Corp.), $100 \mathrm{U} / \mathrm{ml}$ penicillin and $100 \mu \mathrm{g} / \mathrm{ml}$ streptomycin in $5 \% \mathrm{CO}_{2}$ at $37^{\circ} \mathrm{C}$. A549 cells stably expressing MCL-1 or vector control were established by transfecting pcDNA3.1-HA/MCL-1 or pcDNA3.1 under G418 ( $1 \mathrm{mg} / \mathrm{ml})$. For siRNA transfection, each $25 \mathrm{nM}$ of siRNAs was reverse-transfected using Lipofectamine ${ }^{\mathrm{TM}}$ RNAiMAX (Life Technologies Corp.) following the manufacturer's instructions, and the transfected cells were used for each experiment.

Cell viability assay. Cell viability was quantified using the cell proliferation reagent WST-1 (Dojindo, Japan) or CellTiter-Glo (Promega, Madison, WI, USA). A549 cells, siRNA-reverse transfected A549 cells, or stable MCL-1 expressing A549 cells were incubated for $24 \mathrm{~h}$. The antitumor drugs were then added after pre-treatment with TGF- $\beta$ for $48 \mathrm{~h}$. After additional incubation for the indicated time, WST-1 solution or CellTiter-Glo reagent was added. Absorbance was measured at $450 \mathrm{~nm}$ using a Microplate reader for WST-1 assay and luminescence was measured using a GloMax Multi-detection system (Promega) for CellTiter-Glo assay. The cell viability was determined as percent viability compared with the vehicle control.

Western blot analysis. Whole cell lysates were prepared as described previously (15). The primary antibodies used were E-cadherin, N-cadherin, Snail, MCL-1, BCL2A1/Bfl-1, BCL-xL, PARP and caspase-3 (Cell Signaling Technology, Beverly, MA, USA), hemagglutinin (HA) (Roche,Indianapolis, IN, USA) and $\beta$-actin (Santa Cruz Biotechmology, Santa Cruz, CA, USA). All antibodies were used by x 2000 dilution.

Real-time RT-PCR. Expression of MCL-1 and BCL2A1 mRNA was quantitatively determined by real-time PCR on an ABI PRISM 7300 Real Time PCR System (Life Technologies Corp.). Total RNAs were prepared using the RNeasy Plus Mini kit (Qiagen, Hilden, Germany). Expression level of the targeted mRNAs was normalized to $\beta$-actin mRNA. The primers used were: 5'-TCG TAA GGA CAA AAC GGG AC-3' (sense) and 5'-CAT TCC TGA TGC CAC CTT CT-3' (antisense) for $M C L-1$ mRNA, 5'-CCC GGA TGT GGA TAC CTA TAA GGA GA-3' (sense) and 5'-GTC ATC CAG CCA GAT TTA GGT TCA-3' (antisense) for BCL2Al mRNA, and 5'-GCA CAG AGC CTC GCC TT-3' (sense) and 5'-GTT GTC GAC GAC GAG CG-3' (antisense) for $\beta$-actin mRNA.

Apoptosis assay. Apoptotic cell number was determined using the MUSE Annexin V and Dead Cell kit (Merck KGaA, Darmstadt, Germany) according to the manufacturer's instructions. Briefly, the stable cells were harvested after being treated with cisplatin and diluted with PBS containing $1 \%$ bovine serum albumin (BSA) as a dilution buffer to a concentration of $5 \times 10^{5}$ cells $/ \mathrm{ml}$. Cell suspension $(100 \mu \mathrm{l})$ was then added to $100 \mu 1$ MUSE Annexin V and Dead Cell reagent (2x dilution), incubated for $20 \mathrm{~min}$ at room temperature, and analyzed using the MUSE Cell Analyzer. Total Annexin V-positive cells were determined as apoptotic cells.

\section{Results}

Acquired chemo-resistance in A549 cells associates with TGF- $\beta$-induced EMT. Although the relationship between
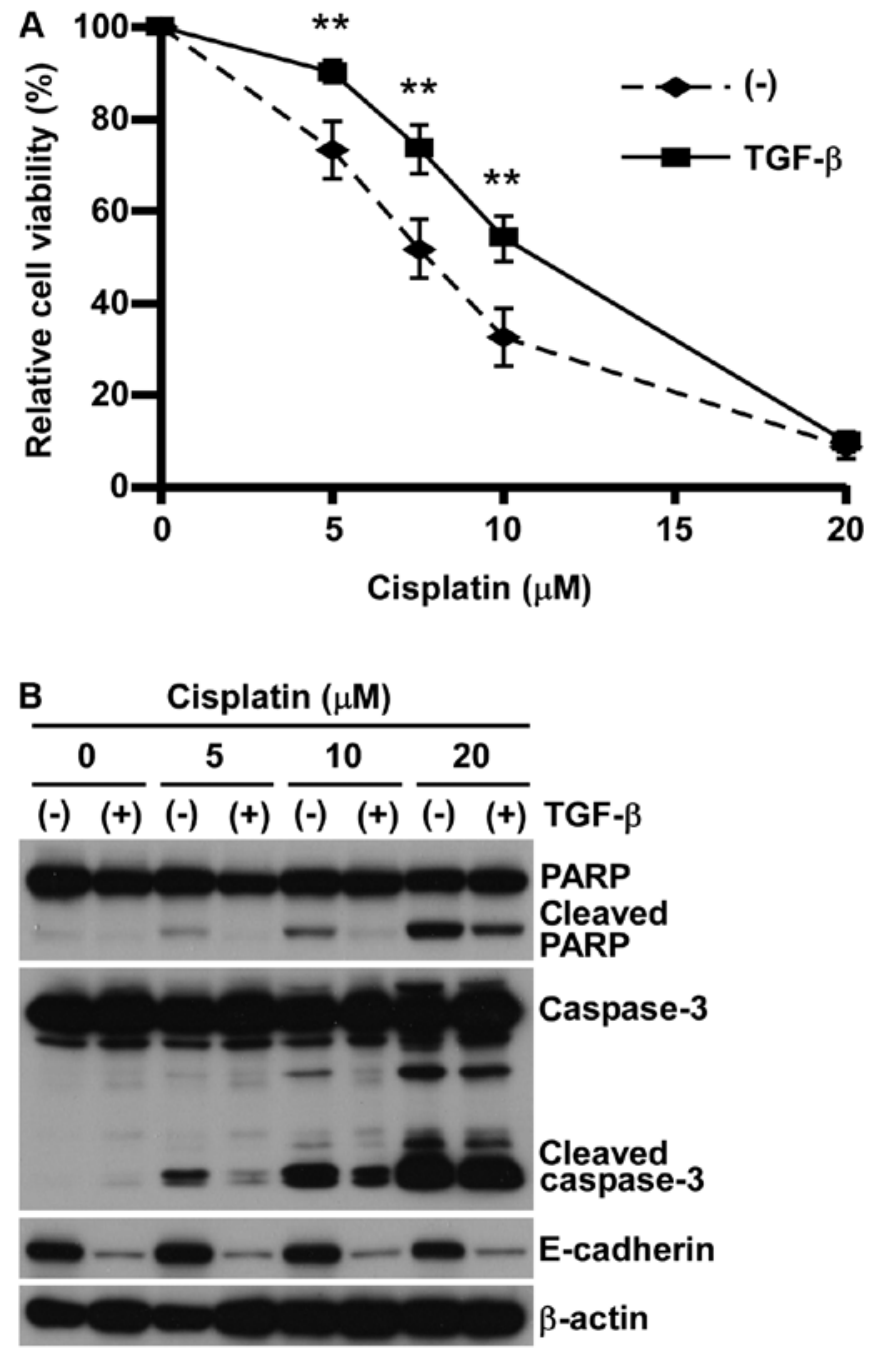

Figure 1. TGF- $\beta$ induces chemo-resistance in A549 cells. (A) A549 cells were incubated with or without $5 \mathrm{ng} / \mathrm{ml}$ TGF- $\beta$ for $48 \mathrm{~h}$, shown as TGF- $\beta$ or (-), respectively. Followed by the treatment with the indicated concentrations of cisplatin for $48 \mathrm{~h}$, cell viability was determined by WST-1 assay. Cell viability was normalized to that in each non-cisplatin-treated cell. ${ }^{* *} \mathrm{p}<0.01$ vs. non-TGF- $\beta$ treatment at each time-point by two-way ANOVA followed by the Bonferroni post-hoc test. (B) Whole cell lysates were subjected to western blotting. Other conditions were similar to (A).

epithelial-to-mesenchymal transition (EMT) and chemoresistance has been implicated $(14,16)$, the detailed molecular mechanism of such EMT-accompanying chemo-resistance has not been determined yet. Therefore, we first tested the various antitumor reagents, such as cisplatin, paclitaxel, gemcitabine, and vinorelbine, in A549 lung adenocarcinoma cell lines with or without inducing EMT by pre-treating with $5 \mathrm{ng} / \mathrm{ml}$ TGF- $\beta(11,17)$. Consistent with our previous studies $(17,18)$, A549 pre-treated with TGF- $\beta$ showed EMT phenotype in both cell morphology and expression of protein markers such as E-cadherin reduction and $\mathrm{N}$-cadherin induction (data not shown). In concert with EMT-induction, A549 cells pretreated with TGF- $\beta$ showed significant resistance against all anticancer reagents tested (Fig. 1A and Table I), which was associated with the reduction of apoptosis marker expression (Fig. 1B). These findings indicate that A549 cells acquired a wide spectrum of chemo-resistance, possibly through apoptosis inhibition associated with EMT induced by TGF- $\beta$. 
A

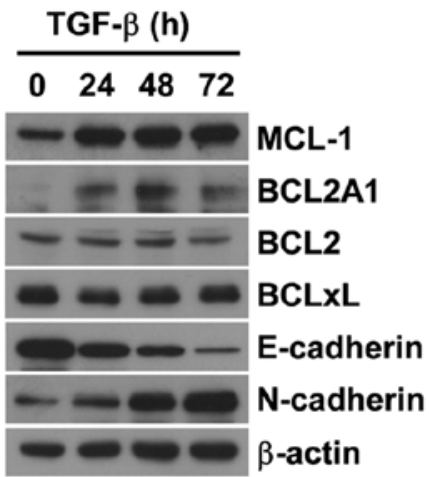

B

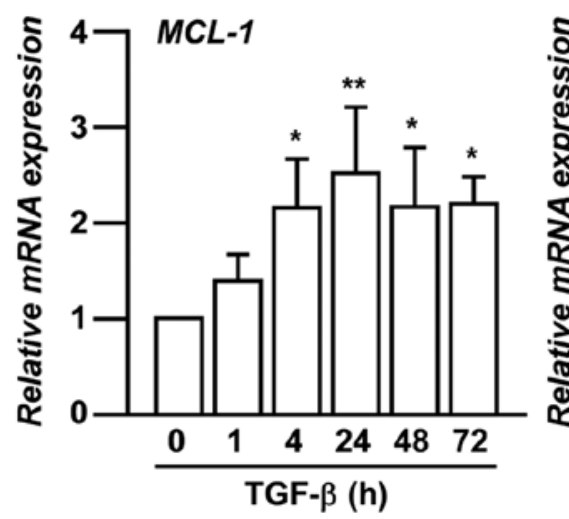

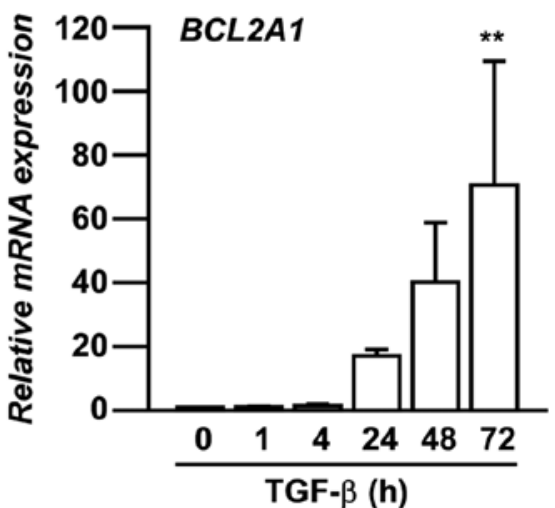

Figure 2. TGF- $\beta$ induces MCL-1 and BCL2A1 in A549 cells. (A) A549 cells were incubated with $5 \mathrm{ng} / \mathrm{ml}$ TGF- $\beta$ for the indicated time. Whole cell lysates were subjected to western blotting. Other conditions were similar to Fig. 1B. (B) A549 cells were treated with $5 \mathrm{ng} / \mathrm{ml}$ TGF- $\beta$ for the indicated times. $M C L-1$ (left panel) and BCL2A1 (right panel) mRNA were quantified by real-time RT-PCR. Relative mRNA expression was normalized to the value of each mRNA at $0 \mathrm{~h}$. Data are shown as the mean $\pm \mathrm{SD}$ of three independent experiments. ${ }^{* *} \mathrm{p}<0.01$ or ${ }^{*} \mathrm{p}<0.05 \mathrm{vs}$. mRNA expression at $0 \mathrm{~h}$ by one-way ANOVA followed by the Bonferroni post-hoc test.

Table I. $\mathrm{IC}_{50}$ of various anticancer drugs in TGF- $\beta$-induced chemo-resistance.

\begin{tabular}{lcc}
\hline & \multicolumn{2}{c}{$\mathrm{IC}_{50}{ }^{\mathrm{a}}($ mean $\pm \mathrm{SD})$} \\
\cline { 2 - 3 } & \multicolumn{1}{c}{$\mathrm{A} 549$} & A549/TGF- $\beta$ \\
\hline Cisplatin $(\mu \mathrm{M})$ & $7.6 \pm 0.8$ & $10.6 \pm 0.8^{\mathrm{b}}$ \\
Paclitaxel $(\mathrm{nM})$ & $11.1 \pm 1.1$ & $22.4 \pm 7.4^{\mathrm{b}}$ \\
Gemcitabine $(\mu \mathrm{M})$ & $0.75 \pm 0.2$ & $>40^{\mathrm{b}}$ \\
Vinorelbine $(\mathrm{nM})$ & $15.8 \pm 3.0$ & $29.1 \pm 6.9^{\mathrm{b}}$ \\
\hline
\end{tabular}

anhibitory concentration at $50 \%\left(\mathrm{IC}_{50}\right)$ was determined by WST-1 assay at $48 \mathrm{~h}$. The values were calculated with data from at least three independent experiments. ${ }^{b} \mathrm{p}<0.05$ compared with A549 cells.

Critical role of MCL-1 in A549 chemo-resistance associated with TGF- $\beta$-induced EMT. We next investigated the expression levels of BCL2 family members in EMT-induced A549 cells. The members are related to chemo-resistance in various cancers by inhibiting apoptosis $(15,19,20)$. Amongst many of BCL2 family members, the expression of MCL-1 and BCL2A1 were specifically increased associated with TGF- $\beta$-induced EMT in A549 cells in a time-dependent manner (Fig. 2A). We further confirmed the increased mRNA expression of $M C L-1$ and $B C L 2 A 1$ after TGF- $\beta$ treatments (Fig. 2B) consistent with their protein expression.

In order to further investigate whether either MCL-1 or BCL2A1 is required for EMT-associated chemo-resistance, we employed gene knock-down of MCL-1 or BCL2A1 by using siRNA pools in which four different siRNAs are contained. MCL-1 knock-down rescued the sensitivity to cisplatin treatment in EMT-induced A549 cells contrary to BCL2A1 knock-down which did not show any significant effect (Fig. 3A). Similar results were also confirmed in additional experiments using two siRNAs against MCL-1 with different target sequences (Fig. 3B). Furthermore, MCL-1-overexpression was able to significantly suppress the cisplatin-induced apoptosis in
non-EMT-induced parental A549 cells (Fig. 3C). Collectively, these results strongly support the critical contribution of MCL-1 in acquiring EMT-associated chemo-resistance in A549 cells.

MCL-1 inhibition by pan-BCL2 inhibitor treatment overcomes $T G F-\beta$-induced chemo-resistance. To test the clinical application of our findings, we examined the effects of pan-BCL2 inhibitors in EMT-associated chemo-resistance in A549 cells. As shown in Fig. 4A, obatoclax, which has a broad range of inhibition in BCL2 family members including MCL-1, re-sensitized EMT-induced A549 cells to cisplatin toxicity. Of note, the treatment with obatoclax $(100 \mathrm{nM})$ showed only minor effect on TGF- $\beta$-treated A549 cell viability (Fig. 4A). In accordance with re-sensitizing to cisplatin toxicity, we also detected the cleavage of both caspase- 3 and PARP in the combination of obatoclax with cisplatin in EMT-induced A549 cells by TGF- $\beta$ (Fig. 4B). Collectively, these results implicate a clinical advantage for targeting MCL-1 in EMT-associated cisplatin-resistance in A549 cells.

\section{Discussion}

In this study, we demonstrated that human NSCLC A549 acquired chemo-resistance upon TGF- $\beta$-induced EMT and such EMT-associated chemo-resistance was mediated through MCL-1-dependent anti-apoptotic pathway. By treating with pan-BCL2 inhibitor, obatoclax, EMT-associated chemoresistance in A549 cells can be reversed, therefore we propose that pharmacological inhibition of MCL-1 could be an attractive target to overcome EMT-associated chemo-resistance and further inhibit metastasis spread in NSCLC patients.

Although MCL-1 was a key molecule in EMT-associated chemo-resistance in this study (Fig. 3), other BCL-2 family members are known to contribute for chemo-resistance in general. For example, enhanced BCL-2 expression is involved in nicotine- or matrilysin-induced cisplatin-resistance in lung cancer cells $(21,22)$ and BCL2A1 confers resistance to BRAF inhibitors in melanoma (15). Considering other EMT inducers 
A

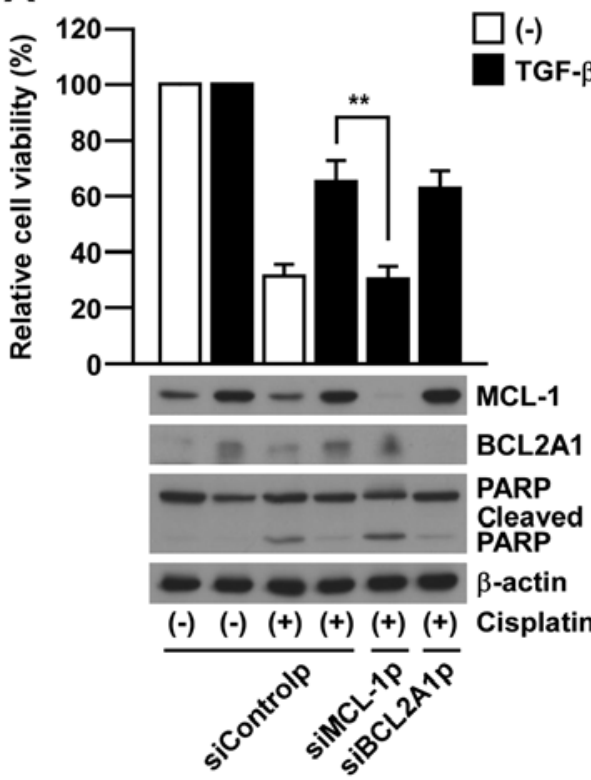

B

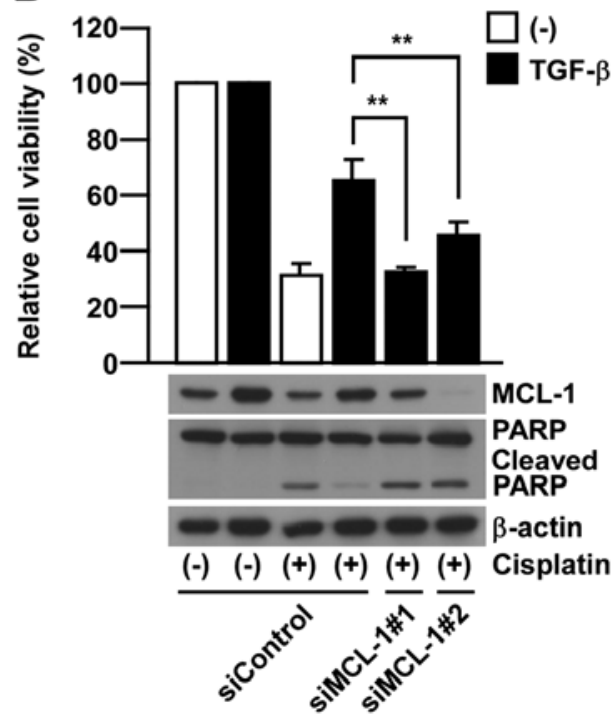

C

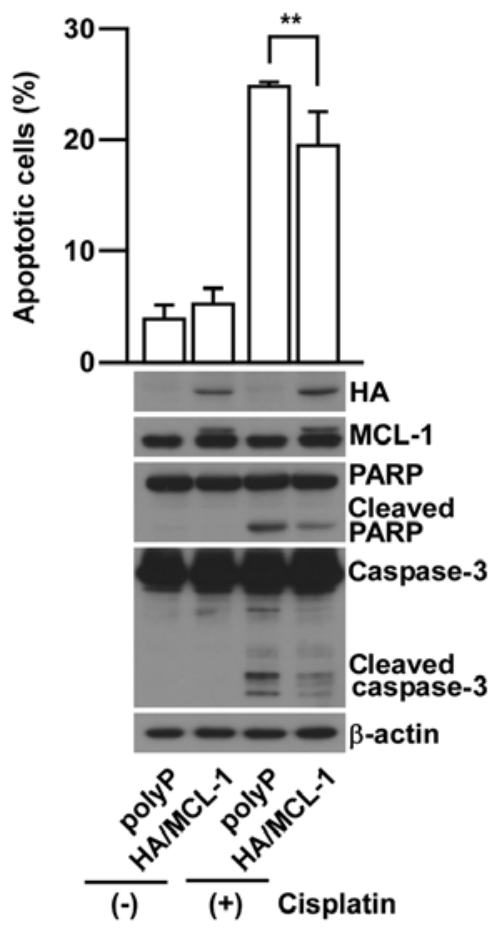

Figure 3. MCL-1 is essential and sufficient to TGF- $\beta$-induced chemo-resistance. (A) A549 cells were transefected with control siRNA pool (siControlp) or siRNA pool against MCL-1 (siMCL-1p) or BCL2A1 (siBCL2A1p). At $24 \mathrm{~h}$ after transfection, $5 \mathrm{ng} / \mathrm{ml}$ TGF- $\beta$ was added and cells were cultured for $48 \mathrm{~h}$. Then the cells were exposed to cisplatin for $24 \mathrm{~h}$ (western blotting) or $48 \mathrm{~h}$ (WST-1 assay). ${ }^{* *} \mathrm{p}<0.01$ compared to siControl pool with TGF- $\beta$ and cisplatin by one-way ANOVA followed by the Bonferroni post-hoc test. (B) A549 cells were transefected with control siRNA (siControl) or siRNA against MCL-1 (siMCL-1\#1 and siMCL-1\#2). Other conditions are similar to (A). (C) A549 cells stably overexpressing HA/MCL-1 (HA/MCL-1) or polypeptides (polyP) were exposed to cisplatin for $24 \mathrm{~h}$ (western blotting) or $48 \mathrm{~h}$ (Annexin V and Dead Cell assay). ${ }^{* *} \mathrm{p}<0.01$ compared with polyP with cisplatin by two-way ANOVA followed by the Bonferroni post-hoc test.
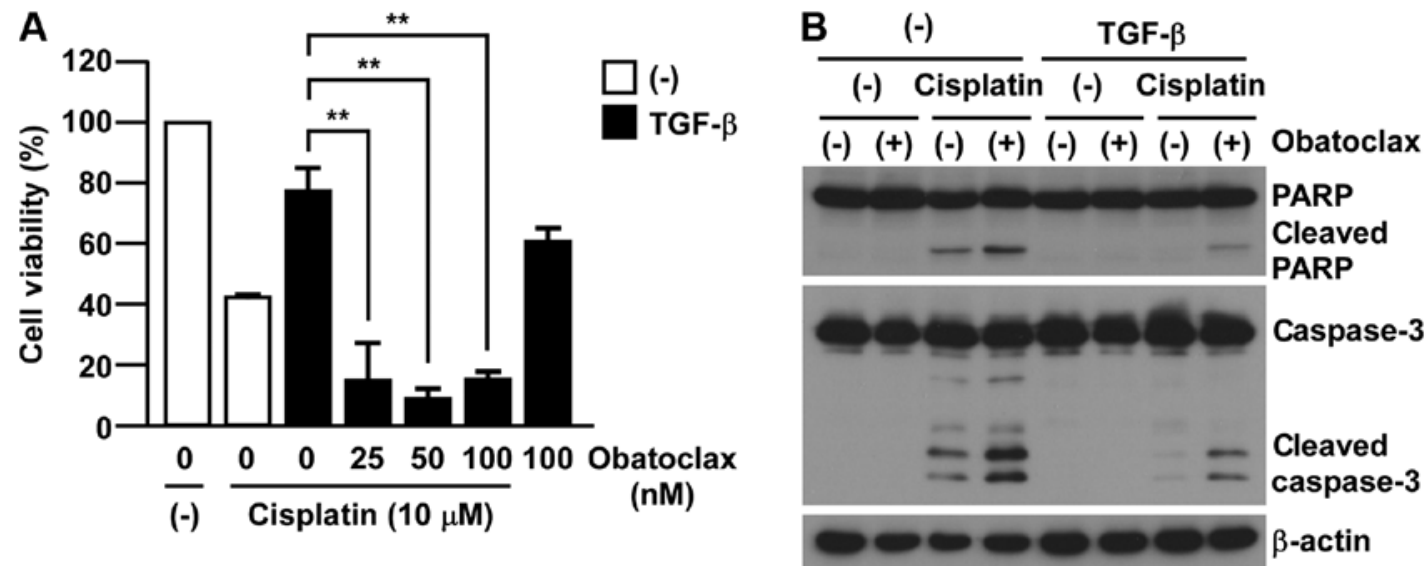

Figure 4. Obatoclax mesylate overcomes TGF- $\beta$-induced chemo-resistance. (A) A549 cells were incubated with or without 5 ng/ml TGF- $\beta$ for 48 h, shown as TGF- $\beta$ or (-), respectively. Followed by the treatment with the indicated concentrations of obatoclax mesylate or $10 \mu \mathrm{M}$ cisplatin for $48 \mathrm{~h}$, cell viability was determined by CellTiter-Glo assay. Cell viability was normalized to that in each non-cisplatin/obatoclax-treated cells. ${ }^{* *}$ p $<0.01$ compared with TGF- $\beta /$ cisplatin-treated cells by one-way ANOVA followed by the Bonferroni post-hoc test. (B) Cisplatin (10 $\mu \mathrm{M})$ or obatoclax mesylate (100 $\mathrm{nM})$ were added after the incubation for $48 \mathrm{~h}$ with or without TGF- $\beta$. Other conditions are similar to (A). Whole cell lysates were subjected to western blotting.

in tumor microenvironment, EGF or HGF, have been reported to induce both EMT and MCL-1 expression (20,23-26), MCL-1 induction might be a common mechanism for EMT-associated chemo-resistance. Although we do not show any direct connection between TGF- $\beta$ and MCL-1, there are several reports that the EMT-related transcription factors, ZEB1 or Twist1, can regulate MCL-1 expression $(27,28)$. In this context, we observed the induction of ZEB1 expression in A549 cells after TGF- $\beta$ treatment (data not shown). Collectively, these observations suggest that ZEB1-mediated transcriptional control can be involved in EMT-associated chemo-resistance by regulating MCL-1 expression. Nevertheless, our current results implicate that mesenchymal-transitioned NSCLC could acquire the chemo-resistance through the induction of MCL-1. Consistent 
with our findings, it is reported that EMT can be observed in the tumor specimens resected from NSCLC patients after chemo-radiotherapy (14) to acquire chemo-resistance $(14,16)$; therefore, these lines of evidence support a clinical relevance of our presented findings. Importantly, we have demonstrated the importance of pharmacological targeting of MCL-1 to re-sensitize cisplatin treatment in A549 cells. In addition to its importance in EMT-associated chemo-resistance shown in this study, MCL-1 is involved in anoikis-resistance in NSCLCs, which can be critical for the survival of tumor cells during the metastatic process (29).

In conclusion, we newly identified MCL-1 as a key molecule for acquiring EMT-associated chemo-resistance in human NSCLC. Considering EMT-associated MCL-1 induction might play critical roles not only in chemo-resistance, but also metastatic spread and survival in distant tissue, pharmacological targeting of MCL-1 provides a new therapeutic opportunity in NSCLC particularly for combining with postoperative chemotherapies.

\section{Acknowledgements}

The authors would like to thank David E. Fisher (MGH, Boston, MA, USA) for kindly giving the plasmids and all members of the Saiki laboratory for discussions and suggestions. This study was supported in part by Grant-in-Aid for Young Scientists (B) 24701023 (M.T.), and 24700971 (S.Y.), by Grants-in-aid for Challenging Exploratory Research 24659348 (I.S.) from the Ministry of Education, Culture, Sports, Science, and Technology (Japan), and by Grant for young scientists from Hokuriku-Bank (S.Y.).

\section{References}

1. Ohe Y, Ohashi Y, Kubota K, et al: Randomized phase III study of cisplatin plus irinotecan versus carboplatin plus paclitaxel, cisplatin plus gemcitabine, and cisplatin plus vinorelbine for advanced non-small-cell lung cancer: Four-Arm Cooperative Study in Japan. Ann Oncol 18: 317-323, 2007.

2. Groome PA, Bolejack V, Crowley JJ, et al: The IASLC Lung Cancer Staging Project: validation of the proposals for revision of the $\mathrm{T}, \mathrm{N}$, and $\mathrm{M}$ descriptors and consequent stage groupings in the forthcoming (seventh) edition of the TNM classification of malignant tumours. J Thorac Oncol 2: 694-705, 2007.

3. Ginsberg RJ and Rubinstein LV: Randomized trial of lobectomy versus limited resection for T1 N0 non-small cell lung cancer. Lung Cancer Study Group. Ann Thorac Surg 60: 613-622, 1995.

4. Carr SR, Schuchert MJ, Pennathur A, et al: Impact of tumor size on outcomes after anatomic lung resection for stage 1A non-small cell lung cancer based on the current staging system. J Thorac Cardiovasc Surg 143: 390-397, 2012.

5. Douillard JY, Rosell R, De Lena M, et al: Adjuvant vinorelbine plus cisplatin versus observation in patients with completely resected stage IB-IIIA non-small-cell lung cancer (Adjuvant Navelbine International Trialist Association [ANITA]): a randomised controlled trial. Lancet Oncol 7: 719-727, 2006.

6. Arriagada R, Bergman B, Dunant A, Le Chevalier T, Pignon JP and Vansteenkiste J: Cisplatin-based adjuvant chemotherapy in patients with completely resected non-small-cell lung cancer. N Engl J Med 350: 351-360, 2004.

7. Winton T, Livingston R, Johnson $\mathrm{D}$, et al: Vinorelbine plus cisplatin vs. observation in resected non-small-cell lung cancer. N Engl J Med 352: 2589-2597, 2005.
8. Fidler IJ: The pathogenesis of cancer metastasis: the 'seed and soil' hypothesis revisited. Nat Rev Cancer 3: 453-458, 2003.

9. Chaffer CL and Weinberg RA: A perspective on cancer cell metastasis. Science 331: 1559-1564, 2012.

10. Ledford H: Cancer theory faces doubts. Nature 472: 273, 2011.

11. Thiery JP: Epithelial-mesenchymal transitions in tumour progression. Nat Rev Cancer 2: 442-454, 2002.

12. Tsai JH, Donaher JL, Murphy DA, Chau S and Yang J: Spatiotemporal regulation of epithelial-mesenchymal transition is essential for squamous cell carcinoma metastasis. Cancer Cell 22: 725-736, 2012.

13. Rho JK, Choi YJ, Lee JK, et al: Epithelial to mesenchymal transition derived from repeated exposure to gefitinib determines the sensitivity to EGFR inhibitors in A549, a non-small cell lung cancer cell line. Lung Cancer 63: 219-226, 2009.

14. Shintani Y, Okimura A, Sato K, et al: Epithelial to mesenchymal transition is a determinant of sensitivity to chemoradiotherapy in non-small cell lung cancer. Ann Thorac Surg 92: 1794-1804, 2011.

15. Haq R, Yokoyama S, Hawryluk EB, et al: BCL2A1 is a lineagespecific antiapoptotic melanoma oncogene that confers resistance to BRAF inhibition. Proc Natl Acad Sci USA 110: 4321-4326, 2013.

16. Thomson S, Buck E, Petti F, et al: Epithelial to mesenchymal transition is a determinant of sensitivity of non-small-cell lung carcinoma cell lines and xenografts to epidermal growth factor receptor inhibition. Cancer Res 65: 9455-9462, 2005.

17. Kato S, Hayakawa Y, Sakurai H, Saiki I and Yokoyama S: Mesenchymal-transitioned cancer cells instigate the invasion of epithelial cancer cells through secretion of WNT3 and WNT5B. Cancer Sci 105: 281-289, 2014.

18. Kin R, Kato S, Kaneto N, et al: Procyanidin C1 from Cinnamomi Cortex inhibits TGF- $\beta$-induced epithelial-to-mesenchymal transition in the A549 lung cancer cell line. Int J Oncol 43: 1901-1906, 2013.

19. Li J, Viallet J and Haura EB: A small molecule pan-Bcl-2 family inhibitor, GX15-070, induces apoptosis and enhances cisplatininduced apoptosis in non-small cell lung cancer cells. Cancer Chemother Pharmacol 61: 525-534, 2008.

20. Henson ES, Gibson EM, Villanueva J, Bristow NA, Haney N and Gibson SB: Increased expression of Mcl-1 is responsible for the blockage of TRAIL-induced apoptosis mediated by EGF/ErbB1 signaling pathway. J Cell Biochem 89: 1177-1192, 2003.

21. Liu H, Zhang T, Wu B, Huang J, Zhou Y and Zhu J: Chronic exposure to exogenous matrilysin induces chemoresistance and enhances Bcl-2 expression in A549 lung adenocarcinoma cells. Mol Biol Rep 36: 2099-2109, 2009.

22. Nishioka T, Luo LY, Shen L, et al: Nicotine increases the resistance of lung cancer cells to cisplatin through enhancing Bcl-2 stability. Br J Cancer 110: 1785-1792, 2014.

23. Leu CM, Chang C and Hu C: Epidermal growth factor (EGF) suppresses staurosporine-induced apoptosis by inducing mcl-1 via the mitogen-activated protein kinase pathway. Oncogene 19: $1665-1675,2000$.

24. Lu Z, Ghosh S, Wang Z and Hunter T: Downregulation of caveolin-1 function by EGF leads to the loss of E-cadherin, increased transcriptional activity of beta-catenin, and enhanced tumor cell invasion. Cancer Cell 4: 499-515, 2003.

25. Hu P, Chu GC, Zhu G, et al: Multiplexed quantum dot labeling of activated c-Met signaling in castration-resistant human prostate cancer. PLoS One 6: e28670, 2011.

26. Schulze-Bergkamen H, Brenner D, Krueger A, et al: Hepatocyte growth factor induces $\mathrm{Mcl}-1$ in primary human hepatocytes and inhibits CD95-mediated apoptosis via Akt. Hepatology 39: 645-654, 2004.

27. Jin HO, Hong SE, Woo SH, et al: Silencing of Twist1 sensitizes NSCLC cells to cisplatin via AMPK-activated mTOR inhibition. Cell Death Dis 3: e319, 2012.

28. Sanchez-Tillo E, Fanlo L, Siles L, et al: The EMT activator ZEB1 promotes tumor growth and determines differential response to chemotherapy in mantle cell lymphoma. Cell Death Differ 21: 247-257, 2014.

29. Li Z,Zhao J, Du Y, et al: Downregulation of 14-3-3zeta suppresses anchorage-independent growth of lung cancer cells through anoikis activation. Proc Natl Acad Sci USA 105: 162-167, 2008. 